\title{
Improved medical and surgical management of cervical spine disease in patients with rheumatoid arthritis over 10 years
}

\author{
Jennifer D Hamilton, Margaret-Mary Gordon, Iain B McInnes, Robin A Johnston, \\ Rajan Madhok, Hilary A Capell
}

\begin{abstract}
Objectives-(1) To compare clinical outcome and symptomatology of rheumatoid cervical myelopathy between patients managed conservatively and surgically. (2) To determine if surgical outcome has improved since the series published from this unit in 1987. (3) To examine the role of magnetic resonance imaging (MRI) in the diagnosis of cervical myelopathy.

Methods-Patients undergoing MRI of the cervical spine between 1991 and 1996 were identified. Case records were reviewed retrospectively.
\end{abstract}

Results-111 patients with RA underwent 124 MRI scans. The median age at onset of cervical spine symptoms was 58 years (range 16-87) with median disease duration of 16 years (range 1-59). 18 (16\%) required surgery immediately after MRI. $93(84 \%)$ were managed conservatively, 9 of whom (10\%) later required surgery. 2/7 deaths in the conservative group were directly related to cervical myelopathy. Patients requiring surgery were more likely to report paraesthesia, weakness, unsteadiness and to exhibit extensor plantar reflexes, gait disturbance, and reduced power. MRI findings did not correlate with clinical features. When compared with the 1974-82 cohort, fewer patients had severe myelopathy (Ranawat grade IIIB) before surgery (34\% versus $7 \%)$. Early postoperative mortality improved from $9 \%$ to $0 \%$ and surgical complication rate fell from $50 \%$ to $22 \%$. $89 \%$ of patients in the 1991-96 cohort reported subjective improvement in overall function.

Conclusion-In this series surgical outcome has improved. The major factor in this more favourable outcome is probably that patients presenting with rheumatoid cervical myelopathy are now referred for surgery at an earlier stage of disease. Clinical findings correlate poorly with MRI findings, therefore clinical history should remain the key to determining the need for MRI.

(Ann Rheum Dis 2000;59:434-438)

Rheumatoid arthritis (RA) commonly affects the cervical spine, with clinically significant disease observed in up to $80 \%$ of patients after 10 years. ${ }^{1}$ As the morbidity of neck disease is considerable, the role of surgery in modifying clinical outcome is clearly of interest. This unit previously examined the outcome of cervical stabilisation in 32 patients between 1974 and 1982 with a mean follow up of 5 years $^{2}$ and suggested that earlier diagnosis of cervical myelopathy was the key to improved surgical outcome. Several other series have arrived at similar conclusions, ${ }^{3-6}$ including a recent, prospective study. ${ }^{7}$

Possibly, the advent of widely accessible magnetic resonance imaging (MRI), together with improved surgical and anaesthetic practices, may have altered surgical outcome. It is currently unclear which patients may require MRI and which will benefit from surgical intervention. Our large clinical centre serves a stable population of approximately 3800 patients with rheumatoid arthritis. This allowed us to re-examine the outcome of cervical spine disease in all patients in whom MRI was performed over six years, and to compare these data with those relating to outcome obtained 10 years previously. Using this cohort, acquired from a 'true life' clinical setting, we have investigated our application of MRI to the diagnosis of cervical spine disease and have compared clinical outcome, regardless of surgical intervention, with that in our previous cohort. Moreover, we sought new factors that might have contributed to poorer outcome.

Patients and methods

Patients with RA attended the rheumatology clinics of five consultant rheumatologists in Glasgow Royal Infirmary (GRI) or Gartnaval General Hospital (GGH) between 1991 and 1996. MRI scans were performed at the Western Infirmary (WI) or Southern General Hospital (SGH) in Glasgow. Neurosurgery was performed in the Institute of Neurological Sciences (INS), a tertiary referral centre for the west of Scotland.

INCLUSION CRITERIA

Patients fulfilled 1987 American College of Rheumatology criteria ${ }^{8}$ and attended either GRI or GGH rheumatology clinics. They had undergone MRI or cervical spine surgery, or both, between 1991 and 1996.

INDICATIONS FOR MRI

All MRI scans were authorised by a consultant rheumatologist using one or more of the following criteria: (a) cervical spine pain not controlled with conservative management; $(b)$ neurological symptoms or signs suggestive of 
Table 1 Clinical and demographic details of the patients. Medians and ranges are shown

\begin{tabular}{lll}
\hline & Surgical $(n=27)$ & Conservative $(n=84)$ \\
\hline Male:female & $1: 8$ & $1: 4$ \\
RF $^{\star}$ positive (No (\%)) & $27(100)$ & $72(86)$ \\
Age symptom onset (years) & $58(23-81)$ & $59.516-87)$ \\
Disease duration symptom onset (median ((range)) & $16(3-49)$ & $16(1-59)$ \\
Joints replaced (No (range)) & $1(0-6)$ & $0(0-5)$ \\
Drug treatment & & \\
$\quad$ Previous DMARDs* (No (range)) & $3(0-10)$ & $2(0-10)$ \\
$\quad$ Receiving prednisolone (No (\%)) & $415)$ & $16(19)$ \\
$\quad$ Previous prednisolone (No (\%)) & $14)$ & $7(8)$ \\
Lifestyle (No (\%)) & & \\
$\quad$ Osteoporosis & $8(30)$ & $37(44)$ \\
$\quad$ Smokers & $4(15)$ & $23(27)$ \\
$\quad$ Ex-smokers & $9(33)$ & $14(17)$ \\
\hline
\end{tabular}

${ }^{\star} \mathrm{RF}=$ rheumatoid factor; DMARDs $=$ disease modifying antirheumatic drugs.

cervical myelopathy; (c) atlantoaxial subluxation on plain $x$ ray. Each rheumatologist had equal access to an MRI scanner.

INDICATIONS FOR SURGERY

Indications for surgery were: $(a)$ uncontrolled cervical spine pain; (b) neurological impairment attributable to cervical spine instability; and (c) progressive radiological appearances.

PATIENT ACQUISITION

Patients referred for MRI of the cervical spine from GRI/GGH between 1991 and 1996 were identified from radiology departmental records. Patients with RA undergoing cervical spine surgery in the INS were identified from the west of Scotland surgical mortality database or GRI/GGH records.

DATA COLLECTION

Data were collected for patients who satisfied inclusion criteria, using the base hospital, and if necessary, the INS case records. These included basic demographic details, relevant symptoms and signs, and reports of radiological appearances on plain cervical spine $x$ ray radiograph and MRI. In those undergoing surgery (group I), details of the operative proce-

Table 2 Symptomatology and examination findings. Results are given as No (\%)

\begin{tabular}{lcc}
\hline & $\begin{array}{c}\text { Surgical } \\
(n=27)\end{array}$ & $\begin{array}{c}\text { Conservative } \\
(n=84)\end{array}$ \\
\hline Symptoms & & \\
Pain & $24(89)$ & $68(81)$ \\
Paraesthesia & $17(63)^{\star}$ & $30(36)$ \\
Weakness & $16(59)^{\star \star}$ & $17(20)$ \\
Unsteady & $11(41)^{\star \star}$ & $4(5)$ \\
Sphincter disturbance & $1(4)$ & 0 \\
Legs “jumping” & $4(15)$ & $6(7)$ \\
None & 0 & $7(8)$ \\
Multiple & $18(67)^{\star}$ & $31(37)$ \\
Signs & & \\
Extensor plantars & $8(30)^{\star \star}$ & $4(5)$ \\
Hyperreflexia & $15(56)$ & $34(40)$ \\
Increased tone & $5(18)$ & $4(5)$ \\
Reduced power & $23(85)^{\star \star}$ & $29(34)$ \\
Off feet & $4(15)$ & $2(2)$ \\
Sensory level & $1(4)$ & 0 \\
Gait disturbance & $8(30)^{\star \star}$ & $2(2)$ \\
Multiple abnormalities & $12(44)^{\star \star}$ & $10(12)$ \\
Normal examination & $5(18)^{\star}$ & $39(46)$ \\
Ranawat grade & & \\
I & $5(18)$ & $57(68)$ \\
II & $12(44)$ & $25(30)$ \\
IIIA & $5(18)^{\star \star}$ & 0 \\
IIIB & $2(7)$ & 0 \\
\hline * $<0.05, \star \star p<0.005 \chi^{2}$ test or Fisher's exact test where appro- \\
priate. & & \\
& &
\end{tabular}

dure and postoperative complications were obtained and Ranawat grade, ${ }^{9}$ symptomatology, and functional change were recorded at the first postoperative visit and annually thereafter. If revision surgery was required, a similar dataset was acquired. In those managed conservatively after MRI (group II), details of symptomatology and Ranawat grade were recorded annually. If neurosurgical intervention was later required, these patients were analysed as for group I.

STATISTICAL ANALYSIS

All information was entered into a Microsoft Access database and analysed with SPSS and Excel software using $\chi^{2}$, Fisher's exact test, and Mann-Whitney tests as appropriate.

\section{Results}

A total of 187 patients who underwent MRI or cervical spine surgery between 1991 and 1996 were identified. Seventy six patients were excluded from the analysis - 55 had diagnoses other than RA and for 21 records were absent. One hundred and eleven patients (approximately $3 \%$ of our rheumatoid population) were referred for MRI, of whom $27(0.7 \%$ of the total rheumatoid population) required surgery. Table 1 gives the relevant clinical and demographic characteristics of these patients, categorised by mode of clinical management. There were no significant differences between the two groups. Neurological symptoms and signs were compared in each group. Those patients who underwent surgery at any time were more likely to report symptoms of paraesthesia, weakness, or unsteadiness and to exhibit extensor plantar reflexes, gait disturbance, and reduced power (table 2). As expected, the surgical group was more likely to be in Ranawat grades II or III. Normal examination findings were more common in conservatively treated patients.

MRI appearances (table 3) were compared with clinical and plain $x$ ray findings. Seven patients with symptoms of cervical pain alone had evidence of cord compression on MRI, despite having normal clinical examination findings. In contrast, nine patients assigned

Table 3 Magnetic resonance imaging (MRI) findings. Results are given as No (\%)

\begin{tabular}{|c|c|c|}
\hline & $\begin{array}{l}\text { Surgical } \\
(n=27)\end{array}$ & $\begin{array}{l}\text { Conservative } \\
(n=84)\end{array}$ \\
\hline \multicolumn{3}{|l|}{ Musculoskeletal } \\
\hline Pannus & $11(41)$ & $36(43)$ \\
\hline Atlantoaxial subluxation & $11(41)$ & $26(31)$ \\
\hline Subaxial subluxation & $7(26)$ & $22(26)$ \\
\hline Vertical subluxation & $2(7)$ & $8(10)$ \\
\hline Cervical spondylosis & $5(18)^{\star}$ & $41(49)$ \\
\hline Cervical disc lesion & $3(11)$ & $17(20)$ \\
\hline Performed in neutral & $18(67)^{\star \star}$ & $76(90)$ \\
\hline \multicolumn{3}{|l|}{ Neurological } \\
\hline Normal & 0 & $7(8)$ \\
\hline Compression of cord & $14(52)^{\star \star}$ & $14(17)$ \\
\hline Impingement on cord & $9(33)^{\star}$ & $13(15.5)$ \\
\hline $\begin{array}{l}\text { or impingement } \\
\text { Vertical subluxation }\end{array}$ & $\begin{array}{l}1(4)^{\star \star} \\
1(4)\end{array}$ & $\begin{array}{c}43(51) \\
4(5)\end{array}$ \\
\hline $\begin{array}{l}\text { Other } \\
\text { Othearuxation }\end{array}$ & 0 & $1(1)$ \\
\hline MRI report missing & 1 & 2 \\
\hline
\end{tabular}
priate. 
Table 4 Causes of death

\begin{tabular}{|c|c|c|c|}
\hline \multicolumn{2}{|l|}{ Conservative group } & \multicolumn{2}{|l|}{ Surgical group } \\
\hline Cause of death & $\begin{array}{l}\text { Time from initial } \\
M R I^{\star} \text { (months) }\end{array}$ & Cause of death & $\begin{array}{l}\text { Time from } \\
\text { initial surgery }\end{array}$ \\
\hline $\begin{array}{l}\text { Perforated bowel } \\
\text { Quadriplegia } \\
\text { Unknown } \\
\text { Acute renal failure } \\
\text { Unknown } \\
\text { Respiratory complication due to cervical } \\
\text { spine disease } \\
\text { Gastrointestinal bleed, renal failure }\end{array}$ & $\begin{array}{l}11 \\
84 \\
39 \\
45 \\
\text { Unknown } \\
16 \\
\text { Unknown }\end{array}$ & $\begin{array}{l}\text { Lung abscess } \\
\text { Acute renal failure }\end{array}$ & $\begin{array}{l}12 \\
78\end{array}$ \\
\hline \multicolumn{4}{|l|}{${ }^{\star} \mathrm{MRI}=$ magnetic resonance imaging. } \\
\hline Primary surgical procedure & & $\begin{array}{l}1974-82 \text { cohort } \\
(n=32)\end{array}$ & $\begin{array}{l}1991-96 \text { cohort } \\
(n=27)\end{array}$ \\
\hline $\begin{array}{l}\text { Anterior fusion } \\
\text { Anterior discetomy and fusion } \\
\text { Anterior discectomy }\end{array}$ & & $\begin{array}{l}1 \\
0 \\
0\end{array}$ & $\begin{array}{l}0 \\
1 \\
1\end{array}$ \\
\hline $\begin{array}{l}\text { Posterior fusion C } 1-2 \\
\text { Posterior fusion }+ \text { laminectomy } \\
\text { Anterior decompression }+ \text { fusion }+ \text { poster }\end{array}$ & ior fixation & $\begin{array}{r}12 \\
4 \\
0\end{array}$ & $\begin{array}{r}12 \\
0 \\
5\end{array}$ \\
\hline $\begin{array}{l}\text { Occipitocervical fusion } \\
\text { Occipitocervical fusion + laminectomy }\end{array}$ & & $\begin{array}{r}12 \\
1\end{array}$ & $\begin{array}{l}6 \\
0\end{array}$ \\
\hline $\begin{array}{l}\text { Other } \\
\text { Not recorded }\end{array}$ & & $\begin{array}{l}0 \\
2\end{array}$ & $\begin{array}{l}2 \\
0\end{array}$ \\
\hline
\end{tabular}

Table 6 Surgical group: comparison of 1974-82 and 1991-96 cohorts

\begin{tabular}{|c|c|c|}
\hline & $1974-82$ cohort $(n=32)$ & $1991-96$ cohort $(n=27)$ \\
\hline $\begin{array}{l}\text { Number of operations } \\
\text { Mean follow up (months) }\end{array}$ & $\begin{array}{l}40 \\
60(24-108)\end{array}$ & $\begin{array}{l}31 \\
26.4(5-78)\end{array}$ \\
\hline $\begin{array}{l}\text { Demographic details } \\
\text { M:F ratio } \\
\text { Median age (years) } \\
\text { Median disease duration (years) }\end{array}$ & $\begin{array}{l}1: 3 \\
\geqslant 60(\text { range } 46-74) \\
\geqslant 18(2-40)\end{array}$ & $\begin{array}{l}1: 8 \\
58(23-81) \\
16(3-49)\end{array}$ \\
\hline $\begin{array}{l}\text { Clinical features }(\%) \\
\text { RF positive } \\
\text { Receiving prednisolone }\end{array}$ & $\begin{array}{l}66 \\
34\end{array}$ & $\begin{array}{l}100 \\
15\end{array}$ \\
\hline $\begin{array}{l}\text { Indication for surgery (\%) } \\
\text { Pain + neurological deficit } \\
\text { Neurological deficit only } \\
\text { Pain only }\end{array}$ & $\begin{array}{l}44 \\
44 \\
13\end{array}$ & $\begin{array}{l}67 \\
11 \\
22\end{array}$ \\
\hline $\begin{array}{l}\text { Ranawat grade (No (\%)) } \\
\text { I } \\
\text { II (mild) } \\
\text { IIIA (moderate) } \\
\text { IIIB (severe) }\end{array}$ & $\begin{array}{l}4(12) \\
11(34) \\
6(19) \\
11(34)\end{array}$ & $\begin{array}{l}5(18) \\
12(44) \\
5(18) \\
2(7)\end{array}$ \\
\hline $\begin{array}{l}\text { Mortality (No (\%)) } \\
\text { No of deaths-early } \\
\text { No of deaths-late }\end{array}$ & $\begin{array}{l}3(9) \\
13(41)\end{array}$ & $\begin{array}{l}0 \\
2(7)\end{array}$ \\
\hline $\begin{array}{l}\text { Morbidity } \\
\text { None } \\
\text { Failure of fusion } \\
\text { Wound infection } \\
\text { Loosening of fixator } \\
\text { Deep infection/abscess } \\
\text { Other }\end{array}$ & $\begin{array}{l}16 \\
9 \\
4 \\
0 \\
1 \\
2\end{array}$ & $\begin{array}{l}21 \\
4 \\
0 \\
1 \\
1 \\
0\end{array}$ \\
\hline
\end{tabular}

clinically to Ranawat grade II had no evidence of cord compression or impingement on MRI. Of 47 patients with axial pannus on MRI, only 24 had atlantoaxial subluxation $(>5 \mathrm{~mm})$ on plain $x$ ray. Six patients had subaxial disease only and three cervical spondylosis alone. Plain $x$ ray appearances, therefore, often diverged from MRI findings. Vertical subluxation on MRI was seen in 10 patients but was represented equally in both treatment groups (table 3).

Thereafter, patients were analysed on the basis of surgical intervention.

Conservative treatment: Outcome measures included survival, the presence of pain, and mobility and ability to live independently as surrogates for functional status. Eighty four patients were managed conservatively throughout with median follow up for 12.5 months (range 4-80). Of the $31 / 84(37 \%)$ who were referred to the neurosurgeons, 12 were discharged and the remaining 19 maintained under neurosurgical review. Seven ( $8 \%$ ) deaths (table 4) occurred, of which two were from causes directly related to cervical myelopathy, 84 and 16 months respectively from the initial MRI. Neck pain over time was reduced in seven patients, unchanged in 42 (50\%), had deteriorated in six (7\%), and was not recorded in 10 cases.

Fifty one $(61 \%)$ patients were independently mobile at the outset compared with 43 (51\%) at the final follow up. Deterioration resulted from neurological disease in two $(2 \%)$ and RA progression in four (5\%) patients. Mobility status was not recorded in $14(17 \%)$ cases.

Surgical treatment: Twenty seven patients underwent a total of 31 surgical procedures (table 5). Nine patients had initially been managed conservatively. Twenty six procedures were performed by one surgeon (RJ), who was appointed after 1982 . The $1974-82$ cohort was broadly comparable with that collected during 1991-96 (table 6), though the initial Ranawat grade was lower and fewer patients received prednisolone in the later cohort.

Outcome was estimated using survival, morbidity, pain, Ranawat grade, and daily function/ mobility. Early and late mortality had clearly improved over 10 years. The two deaths that occurred in the 1991-96 cohort were not directly related to cervical disease (see table 4). Complications of surgery were similar, though episodes of either local infection or failure of fusion had reduced. At three months, pain was absent in $14(52 \%)$ and had improved in nine (33\%). Three patients (11\%) experienced no change. By final follow up-a median of 27 months (range 3-72) later-six patients (22\%) reported a deterioration in symptoms of pain. It was possible from the case sheet to ascertain neurological improvement as assessed by the Ranawat grade in 18 patients at three months and 16 patients at final follow up. At three months the Ranawat grade had improved in six patients and remained unchanged in 12. By final follow up 2/16 patients had experienced neurological deterioration. In contrast 24/27 $(89 \%)$ reported a subjective improvement in overall function at initial neurosurgical review.

Nine patients who were initially managed conservatively required surgery a median of 24 months (range 4-51 months) from the initial MRI. Relevant clinical findings were similar to those of the other conservatively managed patients. However, evidence of compression or impingement on initial MRI was present in all cases. Revision surgery was required in three patients because of failed fusion, increased pain, or neurological deficit. Outcome was poor after revision surgery in each case, with either no change or further deterioration of pain control, neurological deficit, and function. 


\section{Discussion}

The present retrospective study makes several important observations. Surgical outcome after cervical spine stabilisation has apparently improved over the past 10 years in a stable RA population. Early postoperative mortality has fallen from $9 \%$ to $0 \%$ and the surgical complication rate, measured by number of adverse events per surgical procedure, including failure of fusion, infection, or fixator failure, has improved. We, and others, previously suggested that early neurosurgical referral might improve outcome. $^{2-7}$ In our recent cohort, patients underwent surgery with significantly milder myelopathy, as assessed by Ranawat grade, than did patients studied 10 years earlier. This might reflect selection bias inherent in the retrospective design. However, our conservatively treated group did not exhibit an excess of severe disease, making it unlikely that surgical exclusion of such patients could explain all of our findings. Follow up in the current study is shorter and we may have underestimated long term surgical failure. Other factors beyond early referral may have contributed to improved outcome, including modified surgical technique, different surgical personnel, shorter postoperative immobilisation, and improved anaesthetic techniques. Moreover, corticosteroid use has reduced significantly over 10 years, which in the past might have contributed to failed healing. Zoma and colleagues reported pain relief and neurosurgical improvement in $65 \%$ of patients overall. ${ }^{2}$ In the current study $85 \%$ had no pain or reduced pain and $89 \%$ reported subjective functional improvement at the first follow up. These figures compare favourably with those reported elsewhere. ${ }^{35-7}$ Improved access to MRI imaging techniques has clarified distinct advantages of MRI over computed tomography myelography. MRI is non-invasive, provides detailed information about the extent of inflammatory tissue surrounding the odontoid peg, and facilitates dynamic imaging.

Selection of patients requiring MRI in routine practice, however, remains difficult as most patients with RA have cervical spine pain at some stage and, in addition, the threshold for arranging such investigations varies between rheumatologists. This study is unique because MRI and prospective clinical data are available for patients undergoing both conservative and surgical management. Unfortunately, owing to the retrospective design of the study the incidence of significant cervical cord compression in patients not undergoing MRI cannot be estimated because no mechanism for identifying such patients was available. There was a poor correlation between clinical signs and MRI findings, confirming previous observations. ${ }^{10}$ Neurological assessment on rheumatoid patients is exceptionally difficult because of joint deformities, pain, and muscle weakness.

Recently, the predictive value of the posterior atlantodental interval (PADI) has been investigated. An interval $<10 \mathrm{~mm}$ on a plain $x$ ray radiograph ${ }^{3}$ is associated with increased likelihood of spinal cord compression on MRI. It has been suggested that prophylactic surgery should be performed regardless of symptoms when the PADI falls below $14 \mathrm{~mm}$. Such measurements may be useful during surgical decision making. They are, however, likely to be of limited benefit to doctors in deciding from plain $x$ ray appearances which patients to refer for MRI, as a PADI $<14 \mathrm{~mm}$ corresponds with neurological deficit in some $97 \%$ of patients. The PADI was not routinely measured at the time of the original reporting of our radiology films. Similarly, PADIs were unavailable in the previous cohort.

A significant minority of our cohort $(6 \%)$, who presented with neck pain but who exhibited normal neurological examination, had evidence of cord compression on MRI. Pathological series indicate that myelopathy results from long term compression and traction injury to the spinal cord. ${ }^{11}$ Studies are therefore urgently required to determine the proportion of patients with RA without neurological abnormality but with evidence of compression or impingement on MRI. A further critical question concerns whether such patients are at high risk of progression to significant spinal cord disease? Acquisition of such data should also help to predict the timing of neurosurgical intervention. While we await such studies, our data indicate that the clinical history should remain the key to determining the need for MRI, and the subsequent clinical algorithm which may ultimately lead to active surgical intervention.

Our cohort also contained patients in whom MRI was "normal" despite abnormal findings on clinical examination. MRI imaging should include flexion/extension views because a significant increase in spinal cord compression is seen during flexion of the neck in up to $26 \%$ of patients with rheumatoid cervical spine disease.$^{12}$ However, reflecting the true to life nature of the present report, $86 \%$ of MRIs performed in this study were carried out in neutral. This may have resulted from time/ resource constraints on the MRI scanner, patient discomfort (claustrophobia or pain on neck flexion), failure of rheumatologists to specify precise views required, or failure of non-specialist radiologists to recommend such views. Thus, although nine patients in the study were hyperreflexic and had no evidence of compression or impingement on the MRI, it is possible that significant compression on flexion was missed in these patients. In general, however, the presence of reduced power and gait disturbance did correlate with subsequent requirement for surgery.

The successful management of patients with RA requires a team approach. Some patients and general practitioners will have difficulty in recognising the symptoms of cervical myelopathy at each clinic visit. Solutions include adequate education of both the patient and general practitioner and direct inquiry about symptoms of cervical myelopathy, particularly in those with longstanding or severe disease. Close cooperation with radiology departments is essential to ensure that information obtained is adequate for decision making, that flexion/ 
extension MRI views and a PADI is requested. A dedicated, experienced neurosurgical liaison is essential and doctors need to work closely to develop guidelines to determine which patients should be referred for surgery.

Rheumatoid cervical spine disease and cervical myelopathy lead to significant morbidity and mortality. This study illustrates significant problems in determining which rheumatoid patients have significant cervical spine disease. Meticulous attention to clinical skills, prompt referral for appropriate radiology, and neurosurgery input can diminish the adverse impact of this much feared complication of RA.

We thank Professor R D Sturrock, Drs M Field, and J Hunter for allowing us to access data on their patients. We acknowledge the help of Mrs Margaret Brown, Mrs Joyce Shearer, and Miss Helen Wilson in obtaining the appropriate case records, Mrs Helen Burton and the radiology departments at both the Southern General and Western Infirmary for providing the necessary information from the databases, Mr Bryon Jaques fo computing expertise, and Mrs Dorothy Mcknight for her help with statistical analysis.

1 Johnston RA. Review of the spinal complications of rheumatoid disease. Neurosurgery Quarterly 1998;8:206-15.

2 Zoma A, Sturrock RD, Fisher WD, Freeman PA, Hamblen D. Surgical stabilisation of the rheumatoid cervical spine. A review of indications and results. J Bone Joint Surg B 1987;69:8-12.
3 Boden SD, Dodge LD, Bohlman HH, Rechtine CR. Rheumatoid arthritis of the cervical spine. A long term analysis with predictors of paralysis and recovery. J Bone Joint Surg Am 1993;75:1282-97.

4 McRorie ER, Mcloughlin P, Russell T, Beggs I, Nuki G, Hurst NP. Cervical spine surgery in patients with RA: an appraisal. Ann Rheum Dis 1996;55:99-104.

5 Pellicci PM, Ranawat CS, Tsairis P, Bryan WS. A prospective study of the progression of rheumatoid arthritis of the cervical spine. J Bone Joint Surg Am 1981;63:342-50.

6 Santavirta S, Slatis P, Kankaanpaa U, Sandelin J. Treatment of the cervical spine in rheumatoid arthritis. J Bone Joint Surg Am 1988;70:658-67.

7 Casey AT, Crockard HA, Bland JM, Stevens J, Moskovich, Ransford A. Surgery on the rheumatoid cervical spine for the non-ambulant myelopathic patient - too much too late? Lancet 1996;347:1004-7.

8 Arnett FC, Edworthy SM, Bloch DA, McShane DJ, Fries $\mathrm{JF}$, Cooper NS, et al. The American Rheumatism association 1987 revised criteria for the classification of RA. Arthritis Rheum 1988;31:315-24

9 Ranawat CS, O'Leary P, Pellicci P, Tsairis P, Marchisello P, Dorr L. Cervical spine fusion in RA. J Bone Joint Surg Am 1979;61:1003-10.

10 Reijnierse M, Bloem JL, Dijkmans BA, Kroon HM, Holscher HC, Hansen B, et al. The cervical spine in rheumatoid arthritis: relationship between neurologic signs and morphology of $\mathrm{MR}$ imaging and radiographs. Skeletal Radiol 1996;25:113-18.

11 Henderson FC, Geddes JF, Crockard HA. Neuropathology of the brainstem and spinal cord in end stage rheumatoid arthritis: implications for treatment. Ann Rheum Dis 1993; 52:629-37.

12 Dvorak J, Grob D, Baumgartner H, Gschwend N, Grauer W, Larsson S. Functional evaluation of the spinal cord by magnetic resonance imaging in patients with RA and instability of upper cervical spine. Spine 1989;14:1057-64. 